\title{
Chapter 9 \\ Professional Practices in Fixed Assets Valuation and Assessor Education in North America: Suggestions for Japan
}

\author{
Takashi Yamamoto
}

\begin{abstract}
This paper examined and compared the situation of and problems with professional practices in fixed assets valuation and assessor education between North America (the United States and Canada) and Japan. Because professional practice in tax assessment takes place within individual municipalities in North America, the opportunities for external experts to participate in the practice are limited. Moreover, external institutions and universities that provide professional education educated the assessors who were in charge of these professional practices. As a result, the costs of professional practices in tax assessment and assessor education and training have been kept low. In Japan, there has been no foundation through which to foster experts within individual municipalities, so much professional practice is outsourced; consequently, this practice has become ineffective and unstable. Thus, Japan can refer to the North American system of providing complete professional tax assessment services within each municipality, as well as the fostering of experts through external organizations.
\end{abstract}

Keywords Computer-assisted mass appraisal (CAMA) - Street value method . Accountability to taxpayers

\subsection{Introduction}

Regarding fixed assets valuation in Japan, nearly 60 years have passed since the promulgation of valuation standards for fixed assets. The valuation standards are based on the street value method and the process through which valuation standards are developed in Japan differs from that in American and European countries. The fixed assets valuation system in Japan, represented by the street value method, is globally unique. In contrast, fixed assets valuation in North America generally

\footnotetext{
T. Yamamoto $(\bowtie)$

Department of Real Estate Sciences, Meikai University, Urayasu, Chiba, Japan

(C) The Author(s) 2021

Y. Asami et al. (eds.), Frontiers of Real Estate Science in Japan, New Frontiers in

Regional Science: Asian Perspectives 29,

https://doi.org/10.1007/978-981-15-8848-8_9
} 
makes full use of computer-assisted mass appraisal (CAMA), a statistical method. Specifically, this method estimates the appraised value of a place after creating an appraisal model based on a large amount of sales comparison data. Thus, the collection of a large amount of sales comparison data is indispensable. The construction of this appraisal model requires large numbers of people who possess sophisticated expertise and sufficient training. Many people who play a core role in the construction of appraisal models in municipalities in North America have undertaken systematic education in real estate science at a graduate school.

This paper examines and compares the situation regarding professional practices in fixed assets valuation and the education of assessors-who are in charge of the practice- between North America (the United States and Canada) and Japan, as well as the associated problems. Finally, this paper provides certain proposals from a realistic perspective in order to address the current problems associated with land tax assessment in Japan.

\subsection{Professional Practices}

This section compares professional practices in fixed assets valuation between Japan and North America and examines suggestions for professional practice in Japan based on the findings from North America.

\subsubsection{Professional Practice in Japan}

As mentioned above, the CAMA method has been widely used for mass appraisal in North America; however, it has not been adopted for fixed assets valuation in Japan. Instead, the street value method, shown in Fig. 9.1, has mainly been used. The street value method consists of an operation of analyzing land use zones and areas under similar conditions, an operation of appraising standard residential land, ${ }^{1}$ an operation of calculating all street values in neighboring areas under the same conditions based on the street value of a main street and the corresponding value matrix table, ${ }^{2}$ and an operation of calculating all lots facing a street based on the corresponding revision rate table. ${ }^{3}$ Thus, the street value method is a method of valuating land and is characterized by determining the appraised value of land through multiple step-by-

\footnotetext{
${ }^{1}$ A real estate appraiser appraises a standard lot.

${ }^{2}$ The street value of a main street is determined based on the appraised value of standard residential land. All street values in neighboring areas under the same conditions are determined based on indices (obtained when the street value of a main street is set at 100) and the corresponding value matrix table.

${ }^{3}$ For example, the appraised value of a lot with a narrow frontage, a corner lot, etc., is calculated by multiplying the corresponding rate of difference and the street value.
} 
Fig. 9.1 Operational steps of the street value method in Japan

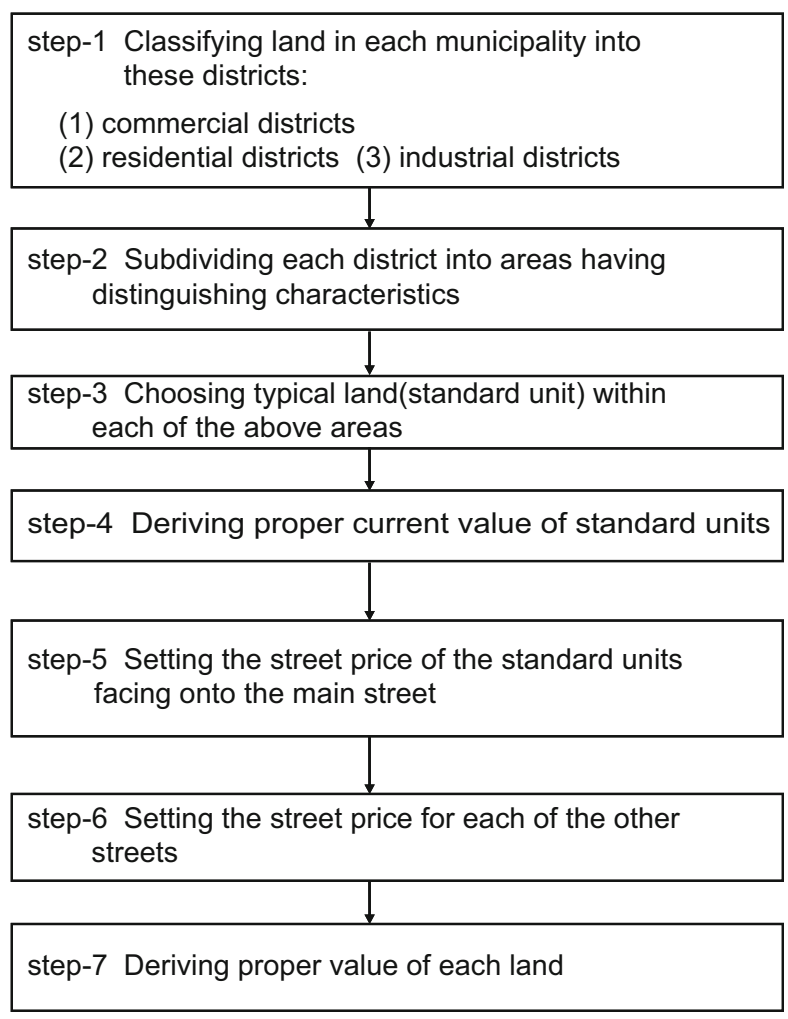

step operational procedures. The advantages of this method are that the progress of these operations can be systematically managed because this method gradually approaches the appraised value of land from a macroscopic perspective to a microscopic perspective, and that the consistency of appraisal can be checked at each operation. As a result, the final accuracy of the appraisal can be increased. The disadvantage of this method is that not only data on each lot but also data on each street must be managed. As a result, data management becomes complicated.

The importance of area analysis is a common point between the CAMA and street value methods. Because the price of real estate is influenced by the area in which it is located, it is necessary to analyze the characteristics of the area and to reflect the analytical results in the appraisal procedure. In the street value method, by calculating the street value using the comparison table, which differs according to the type of land use zone, regionality can be reflected in street value appraisal. 


\subsubsection{Professional Practices in North America}

\section{Construction of an Appraisal Model}

The street value method has been adopted in Japan. In North America, an appraisal model has been widely used, particularly for residential appraisal, based on the results obtained by statistically analyzing sales comparison data. The reasons for this may be as follows:

- In North America, because sales comparison data have been sufficiently prepared, many standardized data sets can be obtained. This is because there are research companies to collect and provide sales comparison data; thus, the data are available for a fee.

- In Japan, there are many dead-end and narrow streets, there are many lots, the prices of which must be largely discounted, and the consideration of individuality is highly necessary, so price estimation using a unitary model is not applicable. In North America, since the street conditions of residential areas are generally excellent, stable price estimation is feasible.

- In Japan, there are many odd-shaped, non-road, extremely small-scale parcels, and many lots for which prices must be largely discounted because of their conditions, so specific consideration must be given to appraisal. In North America, the number of residential areas with lot conditions that have serious problems is small, so no large difference occurs in price estimation using an appraisal model.

In Japan, land and buildings are handled as different pieces of real estate and the price of land is generally higher than that of the building. In North America, the land and building are considered as one unit in principle, so the price of the land is added to that of the building for appraisal. Moreover, the price of a building is generally higher than that of the land in North America. Because a building can easily be specified and an explanatory variable can be used, which can be quantified, the price of a building can easily be estimated using an appraisal model. Thus, a method of estimating the price of a residence using an appraisal model has been widely used.

The basic text of the International Association of Assessing Officers (IAAO), which is a professional education organization for assessors, introduces a hybrid model as a standard appraisal model. ${ }^{4}$ The hybrid model handles the land and building separately using the following formula, and the appraised value of a residence is obtained by adding the price of the building to that of the land.

(General hybrid model)

\footnotetext{
${ }^{4}$ Please refer to p. 121 of Gloudemans (1999), which explains the basic knowledge of mass appraisal.
} 


$$
\mathrm{MV}=\pi \mathrm{GQ} *[(\pi \mathrm{BQ} * \Sigma \mathrm{BA})+(\pi \mathrm{LQ} * \Sigma \mathrm{LA})+\Sigma \mathrm{OA}]
$$

MV: Market price

$\pi \mathrm{GQ}$ : Location quotient

$\pi \mathrm{BQ}$ : Coefficient for a building factor

$\Sigma$ BA: Quantity for a building factor

$\pi$ LQ: Coefficient for a land factor

$\Sigma$ LA: Quantity for a land factor

ऽOA: Quantity for another factor

The above-mentioned hybrid model is just a basic form and is amended by municipalities in many cases. This appraisal model seems to be simple at a glance, but the results obtained using this model differ greatly according to the method of extracting price formation factors and the method of determining each coefficient. It is extremely difficult to construct an appropriate model; thus, a certain degree of expertise is required.

The construction of an appraisal model consists of the following operations: (1) a large number of transactions are collected and arranged, (2) a statistical analysis is performed for the collected and arranged transactions, and (3) a model is designed based on the analytical results. SPSS and NCSS, ${ }^{5}$ which are commercially available statistical analysis software programs, are often used for these operations. Because certain functions that have been customized for assessors are added to NCSS, it is strongly supported by assessment-related persons from the perspectives of economy and convenience.

\section{Use of the Geographic Information System}

Similarly to Japan, the geographic information system (GIS) is an essential tool for fixed assets valuation in North America. The history of using the GIS for fixed assets valuation in North America is longer than that in Japan. In North America, the GIS was diffused, to a certain extent, even in the first half of the 1990s. In Japan, the GIS began to be fully used for professional practice in tax assessment in the second half of the 1990s. At present, there are no major differences in the use of GIS between Japan and North America. Although the basic appraisal method in Japan differs from that in North America, there are many common points between Japan and North America in the use of GIS for the purpose of appraisal. Specifically, the functions of checking and acquiring appraisal data are often used in Japan and North America. For example, a method of analyzing abnormal values in appraisal data using the thematic map function is frequently used in both Japan and North America. However, there is a difference between Japan and North America. In North America, since the response surface analysis method is frequently used to complement sales comparison data, a high-precision location analysis becomes feasible. One of the

\footnotetext{
${ }^{5}$ For the details, please refer to https://www.ncss.com/industries/mass-appraisal/
} 
Table 9.1 Target values of COD and PRD in areas for stand-alone houses

\begin{tabular}{l|l|l}
\hline Category & COD & PRD \\
\hline Newly developed area & 10 or lower & $0.98-1.03$ \\
\hline Residential area & 15 or lower & $0.98-1.03$ \\
\hline Farmhouse area & 20 or lower & $0.98-1.03$ \\
\hline
\end{tabular}

Note: This table was created based on IAAO (1999)

characteristics of appraisal practices in North America is that data obtained using a response surface analysis are reflected in the appraisal model.

SPSS and NCSS are recognized as standard statistical analysis software programs for the construction of appraisal models. In contrast, there is no standard GIS software program.

\section{Ratio Studies}

In North America, ratio studies related to indices have been widely used to secure the reliability of appraisal models. ${ }^{6}$ A ratio study is a method of verification, in which multiple indices are obtained by performing a statistical analysis based mainly on a value obtained by dividing the ratable value of property by the price of a transaction, and the reliability of an appraisal model is estimated based on the obtained indices.

The price-related differential (PRD) and coefficient of dispersion (COD) are particularly important indices in ratio studies. These indices are calculated as follows:

$\mathrm{PRD}=[$ average value of $(A / S)] /[($ average value of $A) /($ average value of $S)]$

$A$ : Ratable value, $S$ : Price of a transaction.

As shown in this formula, when the value of PRD is closer to 1, the relationship between the ratable value and the price of a transaction is presumed to be more stable.

COD is defined by the following formula:

$$
\mathrm{COD}=[\text { mean deviation of } 100 *(A / S)] /[\text { mean value of }(A / S)]
$$

When the value of the COD is large, the dispersion of "ratable value/price of a transaction" is also large. In this case, there is room for improvement on the corresponding appraisal model. Thus, in the ratio studies, indices such as PRD and COD are calculated together with the construction of an appraisal model. Ratio studies have been used to provide back data that are used to verify the accuracy of an appraisal model from multiple perspectives. As shown in Table 9.1, the IAAO provides the desirable target values of these indices.

\footnotetext{
${ }^{6}$ For example, IAAO (1999) describes IAAO's dictum on the ratio studies.
} 
Assessors must always pay attention to these values when constructing an appraisal model. An appraisal model must be constructed so that various indices related to the ratio studies have excellent values. Actually, NCSS automatically calculates various indices.

These values are also used as assessors' performance indices in order to raise their motivation in professional practices. When municipalities disclose information to their taxpayers, these values are sometimes used as explanatory materials to secure the corresponding appraisal.

\section{“Cruces of practices” for North American-Type Mass Appraisal}

The common understanding of assessors is that an excellent appraisal model must satisfy the following four requirements: accuracy, rationality, explainability, and frugality. Japanese appraisal practitioners also emphasize that accuracy, rationality, and explainability are essential. Frugality indicates that a carelessly complicated model is undesirable. If a model with high universality is oriented, a frugal model will be constructed.

\section{Handling of outliers in sales comparison data}

When a statistical analysis is performed using transactions, it is risky to blindly use all data sets. In cases in which the number of samples is small, the analytical results will be highly biased if the data contain outliers. Thus, the collected sales comparison data must be critically examined. Although such a topical idea is understandable, the handling of outliers in individual cases requires delicate prudence. To analyze sales comparison data, it is at least necessary to obtain basic statistics, to create a scatter diagram from multiple perspectives, and to perform a visual examination.

\section{Time adjustment analysis based on economic theory}

The changes in real estate prices in residential areas in North America are more complicated than those in Japan due to the effects of various factors, including seasonal variation and periodicity. Thus, in the operation of time adjustment, it is risky and non-persuasive to simply adopt experience points based on changes in real estate prices in the past. In professional practice in North America, a method developed by referring to the idea of a time-series analysis in the field of econometrics is incorporated into the time adjustment analysis method.

\section{Location analysis organically connected to GIS}

The formation of housing prices is not simple, even in North America, and a highly-explainable appraisal model cannot be constructed based solely on site and building factors, which can be quantitatively understood. To raise the precision of an appraisal model, an idea to reflect the locational characteristics of each house in the model is extremely necessary, as indicated by the location quotient in the above-mentioned hybrid model. GIS is used to acquire data related to the locational characteristics and the locational characteristics can be obtained by three-dimensionally analyzing the distribution of housing prices in sales 
comparison data. This three-dimensional analysis is exactly the above-mentioned response surface analysis, the use of which is one of the characteristics of mass appraisal in North America. Based on a study of Hirayama, et al. (2006, p. 59), the procedure of this analysis is explained as follows:

(a) A regression analysis is performed based on land transactions without considering the location of the property.

(b) Using the regression equation obtained by the analysis, the average value of the predicted land prices corresponding to the transaction is obtained.

(c) By dividing the sale price of each transaction by the obtained average value, a relative price is obtained. The locational condition is considered to be better or worse as the relative price becomes higher or lower (than 1), respectively.

(d) Values corresponding to the $x$ and $y$ axes are given to the location of each transaction. $x$ and $y$ values are also allocated to taxable real estate other than the transactions.

(e) The relative price of each transaction obtained $c$. above is defined as the $z$ value, and the $x, y$, and $z$ values are input into a software program that can draw contour lines.

When these contour lines are three-dimensionally expressed, a sequential curved surface is obtained. This is the reason why the above-mentioned threedimensional analysis is called a response surface analysis. The value corresponding to the height of this curved surface (namely, the $z$ value) is considered as a locational factor, and this factor is added to the appraisal model (the construction of the appraisal model is completed). Thus, GIS plays a complementary role in the general appraisal practice in Japan. In North America, GIS is closely related to the appraisal practice and plays an important role in the appraisal process. This is noteworthy.

4. Roles of ratio studies

Ratio studies play multiple roles. First, they act as a tool to manage the accuracy of mass appraisal practices. In North America, the ratio studies are expected to improve the accuracy of the appraised value of a place by repeatedly constructing appraisal models and providing feedback, similar to the street value method in Japan. Thus, the ratio studies are used as an accurate baseline for mass appraisal. Second, ratio studies play a role as a performance index for assessors. As mentioned above, the role of each officer in a department that performs fixed assets valuation in a municipality is clearly determined. In municipalities, high positions are given to assessors who are experts in the construction of appraisal models. In the evaluation and treatment of an assessor, the results of ratio studies are probably taken into consideration. In North America, assessors often change their place of employment to other municipalities or private consulting firms. The results of ratio studies in the construction of appraisal models are sometimes used to prove the assessor's capability. Third, ratio studies play a role in the implementation of accountability to taxpayers. In North America, the disclosure of information on fixed assets valuation has a good reputation in its historical accumulation and substantial content. In the implementation of accountability 
to taxpayers in relation to tax assessment, the results of ratio studies are sometimes used as supporting data. In a certain state, detailed reports on ratio studies are disclosed to obtain taxpayers' understanding. ${ }^{7}$

\subsubsection{Suggestions for Japan}

Appraisal practices in Japan can refer to the points described below. The first point is the attitude towards attaching weight to the analysis of the real estate market. Mass appraisal in North America gives the impression that it begins with the analysis of transactions and ends with the analysis of transactions, and a lot of time is expended in the analysis of the real estate market. When constructing an appraisal model, a large number of transactions are analyzed from a multidirectional perspective. This is because real estate markets in North America are inhomogeneous, and market trends differ according to cities and regions. The time expended in the analysis of transactions in Japan is considered to be shorter than that in North America. In Japan, after the collapse of the real estate bubble, land prices uniformly declined for a long time. Recently, however, conspicuous upward trends in land prices have been observed in certain cities and regions. In the recent reappraisal of fixed assets, areas where land prices showed upward trends and areas where land prices continuously declined coexisted in many municipalities. Thus, the results of real estate market analyses, which have been carefully performed, become indispensable for providing an explanation to taxpayers.

The second point is the existence of a mechanism to systematically verify the reliability of fixed assets valuation represented by ratio studies. As mentioned above, in North America, ratio studies have been firmly established as a system to raise the reliability of fixed assets valuation. It is noteworthy that due to this system, appropriate competition among assessors and municipalities and a feeling of tension have been maintained. In Japan, there is no firmly established index to specifically measure the reliability of fixed assets valuation. In the future, it is predicted that in professional practice in tax assessment in Japan, improvement in the accuracy of appraisal and the provision of a convincing explanation to taxpayers will be more important than ever before. To cope with this, the possibility of introducing a system similar to ratio studies in North America should be examined.

\footnotetext{
${ }^{7}$ For example, in the State of Washington, the results of ratio studies in each county are summarized and published in the form of a report.
} 


\subsection{Fixed Assets Valuation and Assessor Education Systems}

This section compares fixed assets valuation and assessor education systems between Japan and North America and examines suggestions for appraisal practices in Japan based on knowledge obtained in North America.

\subsubsection{Fixed Assets Valuation and Assessor Education Systems in Japan}

Tax assessment in municipalities in Japan is systematically and technologically supported by the Ministry of Internal Affairs and Communications. Therefore, no large differences exist in tax assessment among municipalities. The Research Center for Property Assessment System periodically provides opportunities for staff training so that the staff of each municipality can acquire basic knowledge on tax assessment.

As the characteristics of the fixed assets valuation system in Japan's municipalities, "job rotation" and a "system of outsourcing to appraisal consultants" can be cited. "Job rotation" and a "system of outsourcing to appraisal consultants" are explained below.

\section{Job rotation}

Job rotation is performed very often in municipalities. For example, the staff of a municipality is assigned to the fixed property tax division from other divisions and from the fixed property tax division to other divisions after approximately 3 years have passed. Thus, it is difficult to foster a staff with sufficient expertise and experience in appraisal practices. Recently, the streamlining of duties, including staff cutbacks, has advanced, and this trend has been clearly noticed.

2. The system of outsourcing to appraisal consulting firms

To solve the above-mentioned problem, many municipalities entrust tax assessment to appraisal consulting firms, including aerial survey companies and real estate appraisal companies (outsourcing of appraisal practices). If a particular appraisal consulting firm is in charge of tax assessment for a long time, the consulting firm can accumulate experience in appraisal practices. As a result, the accuracy and stability of appraisal can be improved. However, if a municipality provides long-term private contracts for tax assessment, the cost of outsourcing will be huge.

To avoid this, municipalities select appraisal consulting firms using a competitive bidding process. This increases the possibility that appraisal consulting firms will be periodically changed. If consulting firms are changed, there is a high risk that the new consulting firm will not take over the accumulated knowledge and data. As a result, appraisal may be unstable. When an officer in a municipality 
who is in charge of tax assessment is not capable of controlling the corresponding consulting firm, inconvenience may occur.

The above-mentioned matters can be summarized as follows: (a) due to job rotation in municipalities, appraisal experts cannot be stably fostered; (b) many municipalities must entrust appraisal practices to external experts; (c) because a competitive bidding process has been recommended in the consignment of tax assessment in recent years, appraisal consulting firms may be changed every 3 years at the time of reappraisal of fixed assets; and (d) appraisal may become unstable. Thus, knowledge on appraisal is not sufficiently accumulated in municipalities. Therefore, it is difficult for staff members with only a few years of experience in tax assessment to consistently explain tax assessment to taxpayers based on the accumulation of past appraisals.

\subsubsection{Fixed Assets Valuation and Assessor Education Systems in North America}

The scales of municipalities vary widely in North America so the organizations in charge of fixed assets valuation in municipalities cannot be simply explained. The differences between North America and Japan are as follows: (1) the absolute number of municipal officers in charge of appraisal is larger in North America, (2) role sharing is more advanced in North America, and (3) some municipal officers are treated as experts in North America. For example, in a municipality with a population of approximately 30,000 , there will be around 50 officers in charge of appraisal. Role sharing is advanced so that municipal officers are classified as officers in charge of GIS, those in charge of the construction of an appraisal model, those in charge of field surveys, etc. Assessors who are mainly responsible for the construction of appraisal models are treated as experts, and are not assigned to other divisions. However, assessors often change their place of employment to other municipalities or private consulting firms.

In Japan, the municipal officers in charge of tax assessment are requested to acquire necessary skills by accumulating actual practice at their workplaces. In the United States, a private organization specialized in assessor education plays an important role.

This organization, the IAAO, is described in Sect. 9.2.2.1 above. The IAAO lays the foundation for training assessors in municipalities in North America. Municipal officers who want to be assessors in North America are asked to undertake training courses sponsored by the IAAO and to earn necessary credits. After earning certain credits, these officers take an examination to obtain a qualification authorized by the IAAO. When these officers pass the examination, the qualification is given to them. The experts' roles and positions in municipalities are according to the qualifications that they have obtained. 
Table 9.2 Assessor qualifications authorized by the IAAO

\begin{tabular}{l|l}
\hline Qualifications & Roles and contents \\
\hline $\begin{array}{l}\text { Certified assessment evalua- } \\
\text { tor (CAE) }\end{array}$ & $\begin{array}{l}\text { The role of a CAE is to supervise all professional practice in tax } \\
\text { assessment. CAE is ranked as the highest qualification among the } \\
\text { qualifications authorized by the IAAO }\end{array}$ \\
\hline $\begin{array}{l}\text { Residential evaluation spe- } \\
\text { cialist (RES) }\end{array}$ & An RES is a specialist in the tax assessment of residences \\
\hline $\begin{array}{l}\text { Mass appraisal specialist } \\
\text { (MAS) }\end{array}$ & $\begin{array}{l}\text { An MAS is a specialist who has systematically acquired specialty } \\
\text { knowledge on mass appraisal technology (data analysis and } \\
\text { appraisal model construction) }\end{array}$ \\
\hline $\begin{array}{l}\text { Assessment administration } \\
\text { specialist (AAS) }\end{array}$ & $\begin{array}{l}\text { An AAS is a specialist who is responsible for the administrative } \\
\text { management of general property tax }\end{array}$ \\
\hline $\begin{array}{l}\text { Personal property specialist } \\
\text { (PPS) }\end{array}$ & A PPS is a specialist in the tax assessment of movable property \\
\hline $\begin{array}{l}\text { Cadastral mapping specialist } \\
\text { (CMS }\end{array}$ & A CMS is a specialist in cadastral mapping \\
\hline
\end{tabular}

At present, the IAAO authorizes six qualifications (Table 9.2). Each qualification corresponds to a specific field of professional practice. Among the six qualifications, certified assessment evaluator (CAE) is ranked as the highest qualification. CAEs are in charge of supervising all professional practice in tax assessment; the immediate goal of many assessors is to obtain this certification.

A point worthy of special mention is that the University of British Columbia in Canada fosters assessors in its graduate school (business school) in cooperation with the IAAO ${ }^{8}$ Due to its effect, the number of assessors who have IAAO qualifications has tended to increase in Canadian municipalities. The IAAO periodically holds research conferences in addition to assessor training. ${ }^{9}$ As a result, appraisal technology has improved, the results obtained by the improved technology have been shared among the IAAO's members, and knowledge on appraisal has been steadily accumulated.

\subsubsection{Suggestions for Japan}

As mentioned above, in North America, because professional practices in tax assessment are completed within a municipality, external experts do not have many opportunities to participate. Moreover, external professional education

\footnotetext{
${ }^{8}$ Please refer to http://www.sauder.ubc.ca/Programs/Real_Estate_Division/Credit_Programs_and_ Professional_Development_Courses

${ }^{9}$ Research conferences with several thousand participants are periodically held in major cities in North America. There are dozens of subcommittees, in which the results of studies in almost all fields of fixed assets valuation are presented and discussed. Approximately $90 \%$ of participants are assessors in North America, and some participants come from developing countries.
} 
institutions and universities positively undertake the education of assessors who are in charge of these professional practices. As a result, the costs of professional practices in tax assessment and assessor education and training are kept low. In Japan, there is no foundation through which to foster experts within each municipality, so many professional practices are outsourced; consequently, these practices become ineffective and unstable. Moreover, assessors seldom cooperate and liaise with special organizations, such as universities. To improve this, Japan can refer to the North American system of completing the professional practice in tax assessment within each municipality, as well as the fostering of experts through external organizations.

\subsection{Certain Proposals}

As mentioned above, the number of highly-specialized persons who can supervise all professional practices in tax assessment in the tax assessment divisions of Japanese municipalities has become insufficient. As a result, various problems occur. To solve this, we propose that the tax assessment division in municipalities should foster individuals who wish to become qualified real estate appraisers, whose positions as specialists in real estate appraisal have been established. In addition to improving the accuracy and efficiency of appraisal practices in municipalities, ${ }^{10}$ this will improve the reliability of tax assessment and facilitate the easy collection of taxes from taxpayers. Finally, definite plans are described below in the summary of this paper.

\subsubsection{Fostering Assessors in Municipalities in Cooperation with Universities}

In Japan, real estate appraisers play a central role in real estate appraisal as national qualification holders. However, after passing the national examination, prospective real estate appraisers must pass a final test after receiving practical training for a certain period of time. These individuals generally receive practical training while working for real estate appraisal companies. Thus, it is difficult for municipal officers to become qualified real estate appraisers. There is a system called "training at university." In this system, a university, which has been authorized as a practical

\footnotetext{
${ }^{10}$ The municipal officers in charge of appraisal are in daily contact with real estate appraisers who are responsible for standard residential land appraisal and for consulting practices in each stage of street value appraisal. To manage the accuracy of the professional practice of external real estate appraisers, these officers, as qualified persons, are requested to have knowledge on real estate appraisal that is equal to or greater than that of external real estate appraisers.
} 
training institution, performs "practical exercises" for practical training. The practical exercises are generally performed outside office workers' working hours. In this case, municipal officers can obtain a real estate appraiser qualification while working for a municipality. By progressively using this system, the number of appraisal specialists in municipalities can be increased.

Meikai University, which is the only university in Japan with a department of real estate (Department of Real Estate Sciences), has also received authorization for "training at university." Meikai University Graduate School of Real Estate Sciences offers various courses, including real estate appraisal, architecture, GIS, statistical analysis, real estate-related laws, real estate-related policies, and real estate accounting. Thus, this graduate school can provide education services in conformity with the IAAO's education and training. In the past, Meikai University accepted a few municipal officers who were in charge of fixed assets valuation. In this case, however, the school expenses were self-paid, the acquisition of the real estate appraiser qualification was categorized as "personal self-development," and no differences were observed in their occupational roles or treatment after acquiring the qualification. If the school expenses are paid by municipal officers who have passed the essay-based examination for real estate appraisers are fully or partially assisted by public expenses, they can receive "training at university." If the personnel treatment system is amended so that municipal officers are ranked as highly skilled professionals after obtaining the qualification, the number of municipal officers who want to be real estate appraisers will increase. Moreover, if municipal officers receive real estate science education at a graduate school together with "training at university," the effect of the training will increase.

\subsubsection{Employment of Real Estate Appraisers by Municipalities}

The number of specialists in real estate appraisal in municipalities can be increased by newly employing real estate appraisers. Although this method increases personnel costs, the personnel costs can be reduced by employing part-time officers. For example, real estate appraisers who have experienced consulting practices in fixed assets valuation in major real estate appraisal companies can be expected as workready persons because they are familiar with practical operations related to the standards for real estate appraisal and the valuation standards for fixed assets. 


\section{References}

Gloudemans RJ (1999) Mass appraisal of real property. IAAO, Kansas City

Hirayama K, Suzuki T, Fujiki K (2006) Trends of fixed assets appraisal in the United Statesintroduction of outsourcing destination selecting methods and attempts of advanced mass appraisal. Real Estate Res 48(1):57-60

IAAO (1999) Standard on ratio studies. Assess J 6(5):23-64

Open Access This chapter is licensed under the terms of the Creative Commons Attribution 4.0 International License (http://creativecommons.org/licenses/by/4.0/), which permits use, sharing, adaptation, distribution and reproduction in any medium or format, as long as you give appropriate credit to the original author(s) and the source, provide a link to the Creative Commons licence and indicate if changes were made.

The images or other third party material in this chapter are included in the chapter's Creative Commons licence, unless indicated otherwise in a credit line to the material. If material is not included in the chapter's Creative Commons licence and your intended use is not permitted by statutory regulation or exceeds the permitted use, you will need to obtain permission directly from the copyright holder.

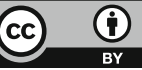

